\title{
Easy and effective counter-traction using a clip with a looped thread for colorectal endoscopic submucosal dissection
}

Colorectal endoscopic submucosal dissection (ESD) remains a difficult endoscopic procedure. Several traction methods have been reported that enable an appropriate view of the submucosal layer; however, almost all of these methods have some problems regarding preparation, delivery, ease or cost [1-4]. We have concluded that "ring-shaped thread counter-traction" is the most effective method to overcome some of these problems [5]. Here, we report a treatment strategy for colorectal ESD using a clip with a looped thread, which has been developed to resemble a ring-shaped thread.

A 3-0 nylon suture and a clip (HX-610135; Olympus, Tokyo, Japan) are used as the material. After making two loops with the 3-0 nylon suture, one of the

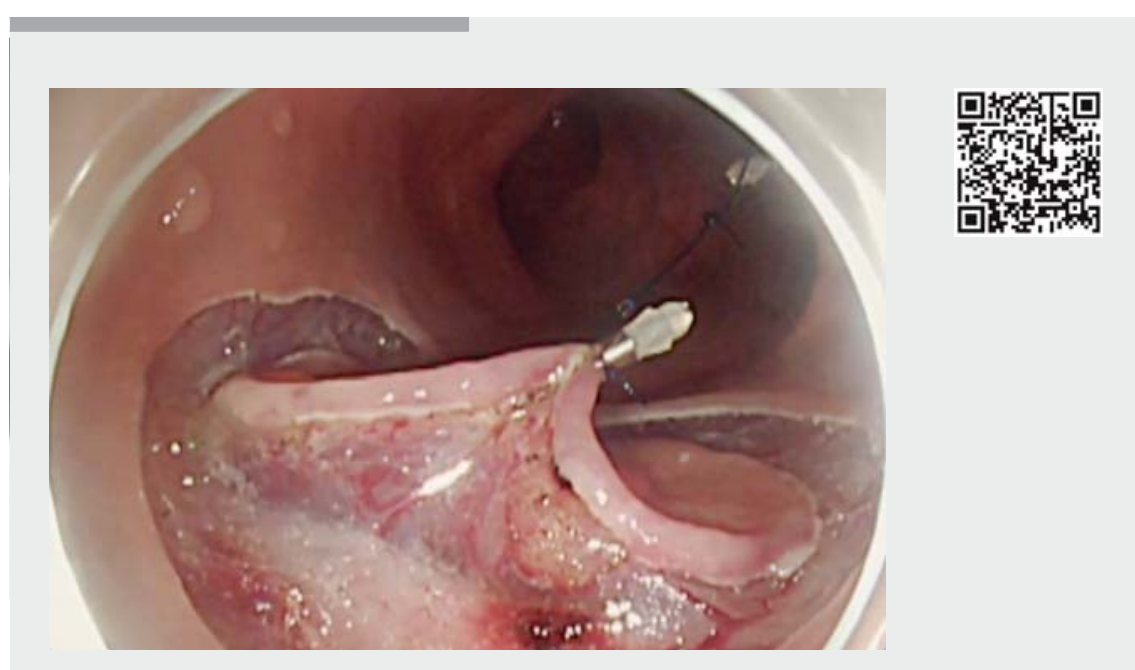

$\checkmark$ Video 1 How to prepare a clip with a looped thread, and colorectal endoscopic submucosal dissection using the clip with looped thread method.
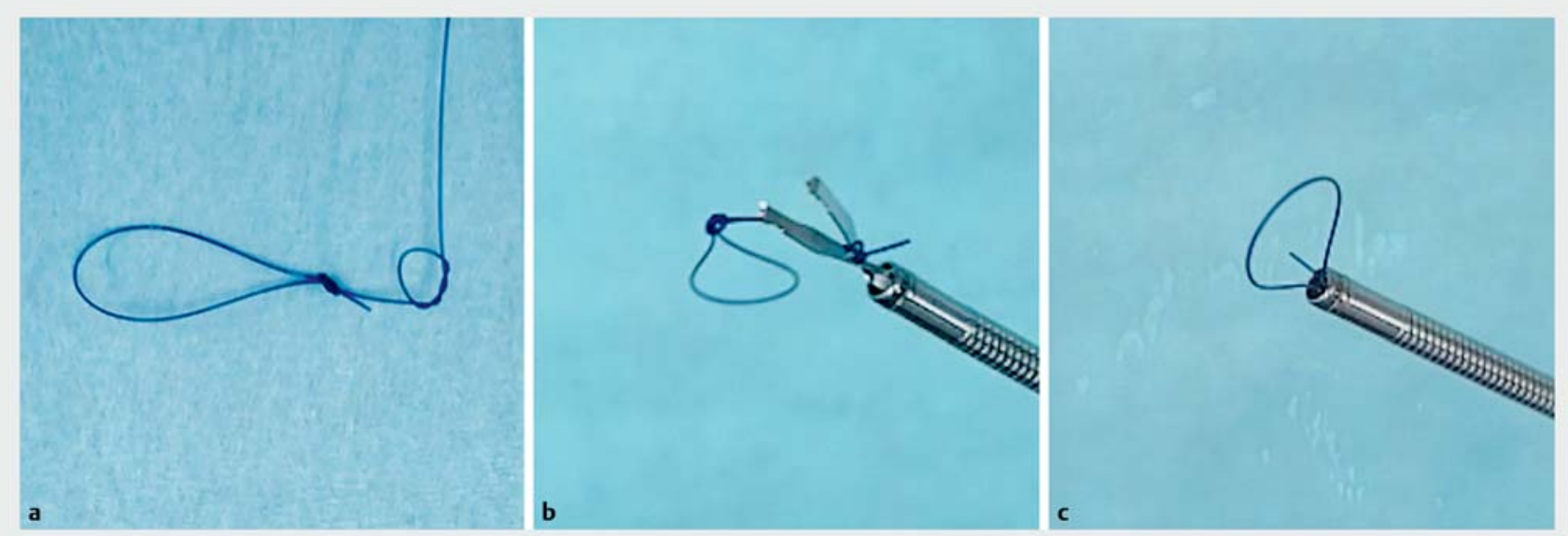

two loops of thread is tied to the arm part of the clip ( $\triangleright$ Fig. 1 ).

First, a mucosal circumferential incision and submucosal dissection are made ( $\triangleright$ Fig.2a,b). Next, a clip with a looped thread is placed at the proximal end of

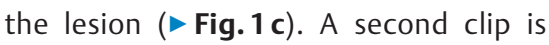
then placed into the loop of thread, and the clip is placed on the contralateral side of the lesion ( $\boldsymbol{F}$ Fig. $2 \mathbf{d}$ ).

By elevating the mucosa, we can maintain good visibility of the submucosal layer, allowing for a safe and speedy dissection. Upon ESD completion, the loop of thread is cut and recovered with the lesion.

This counter-traction method has many advantages. No special tools or devices are necessary, and the procedure can be carried out without the removal and reinsertion of a scope. Additionally, this method is inexpensive, easy, and only requires 30 seconds to make one looped thread. The length of the thread can be adjusted according to the circumstances, and more clips or looped thread can be added as needed. We suggest that this counter-traction method may be one of the best traction methods for colorectal ESD.

- Fig. 1 A clip with a looped thread. a A looped thread. b Tying the looped thread to a clip. c The clip with the looped thread. 


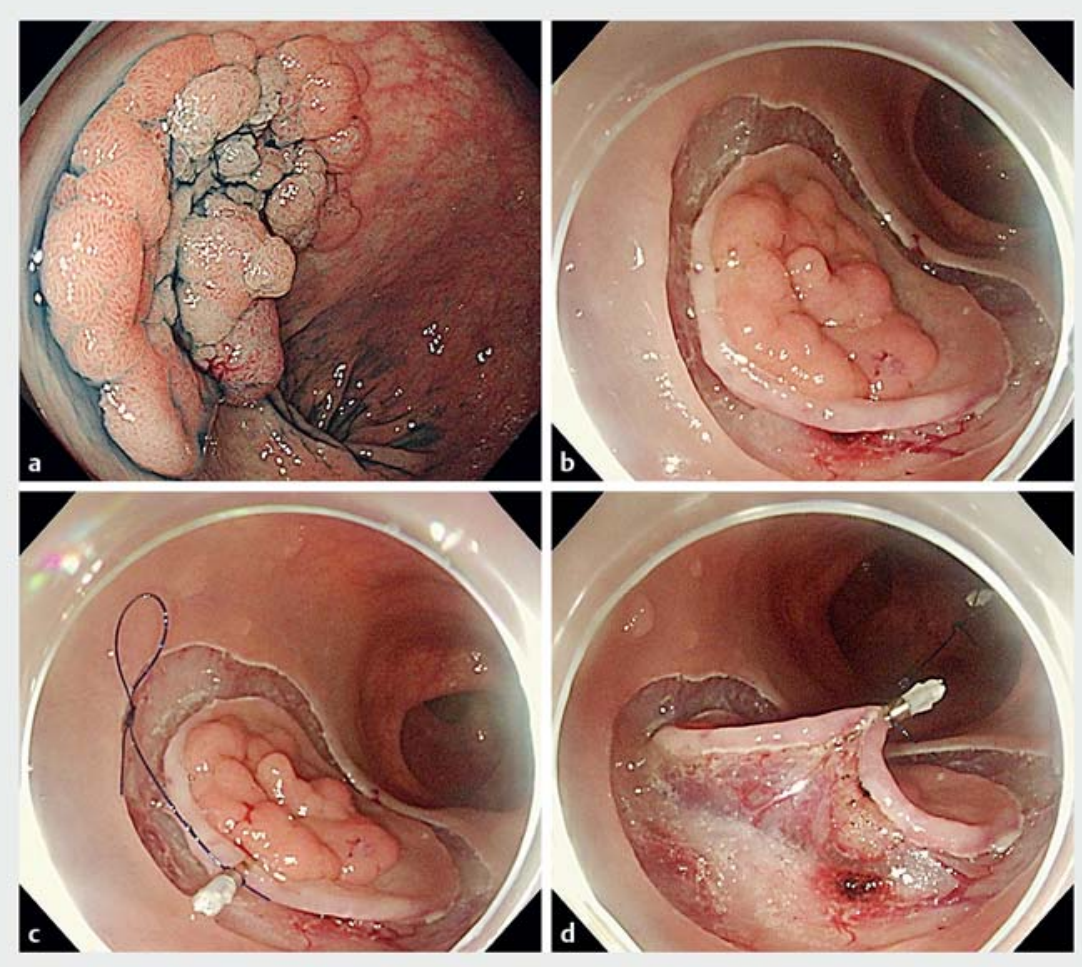

- Fig. 2 Colorectal endoscopic submucosal dissection using a clip with a looped thread. a A granular laterally spreading tumor, $30 \mathrm{~mm}$ in size, in the sigmoid colon. b Circumferential mucosal incision and submucosal dissection. c The first clip with the looped thread is placed at the proximal end of the lesion. $\mathbf{d}$ A second clip is placed on the contralateral side of the lesion.

Endoscopy_UCTN_Code_TTT_1AQ_2AD

The authors

\section{Acknowledgment}

My deepest appreciation goes to Dr. Anami whose enormous support and insightful comments were invaluable during the course of my study. I also owe a very important debt to Dr. Watanabe and Dr. Kitamura whose meticulous comments were an enormous help to me. I would like to express deepest appreciation to American Journal Experts for carefully proofreading the manuscript.

Competing interests

None

Naohiko Indo, Takahiro Anami, Naoki Asaji, Satoshi Urakami, Akihiro Nishio, Yasuaki Kitamura, Akihiko Watanabe

Department of Gastroenterology, Yodogawa

Christian Hospital, Osaka, Japan

\section{Corresponding author}

\section{Naohiko Indo, MD}

Department of Gastroenterology, Yodogawa Christian Hospital, 1-7-50 Kunijima,

Higashiyodogawa-ku, Osaka 533-0024,

Japan

Fax: +81-6-63206308

inchan0701@gmail.com

\section{References}

[1] Kobayashi T, Gotohda T, Tamakawa K et al. Magnetic anchor for more effective endoscopic mucosal resection. Jpn J Clin Oncol 2004; 34: $118-123$

[2] Sakamoto N, Osada T, Shibuya T et al. The facilitation of a new traction device ( $\mathrm{S}-\mathrm{O}$ clip) assisting endoscopic submucosal dissection for superficial colorectal neoplasms. Endoscopy 2008; 40 (Suppl. 02): E94-E95

[3] Yamasaki Y, Takeuchi Y, Uedo N et al. Traction-assisted colonic endoscopic submucosal dissection using clip and line: a feasibility study. Endosc Int Open 2016; 4: E51 - E55

[4] Miura Y, Shinozaki S, Hayashi Y et al. Duodenal endoscopic submucosal dissection is feasible using the pocket-creation method. Endoscopy 2017; 49: 8-14

[5] Mori H, Kobara H, Nishiyama $\mathrm{N}$ et al. Novel effective and repeatedly available ringthread counter traction for safer colorectal endoscopic submucosal dissection. Surg Endosc 2017; 31: 3040 - 3047

\section{Bibliography}

DOI https://doi.org/10.1055/a-0885-9550

Published online: 2.5.2019

Endoscopy 2019; 51: E233-E234

(c) Georg Thieme Verlag KG

Stuttgart · New York

ISSN 0013-726X

\section{ENDOSCOPY E-VIDEOS}

https://eref.thieme.de/e-videos website at

https://mc.manuscriptcentral.com/e-videos 